\title{
The possible different roles of denosumab in prevention and cure breast cancer bone metastases: A 'hypothesis-generator' study from clinical practice
}

\author{
ALESSIO CORTELLINI ${ }^{1,2^{*}}$, VALENTINA COCCIOLONE ${ }^{1,2^{*}}$, AZZURRA IRELLI $^{1,2}$, FRANCESCO PAVESE $^{1,2}$, \\ TINA SIDONI ${ }^{2}$, ALESSANDRO PARISI $^{1,2}$, PAOLA LANFIUTI BALDI ${ }^{2}$, OLGA VENDITTI $^{2}$, CARLA D'ORAZIO $^{1,2}$, \\ PIERLUIGI BONFILI ${ }^{3}$, PIETRO FRANZESE ${ }^{3}$, LUIGI ZUGARO ${ }^{4}$, LUCILLA VERNA ${ }^{1}$, \\ GIAMPIERO PORZIO $^{1,2}$, DANIELE SANTINI ${ }^{5}$, KATIA CANNITA $^{2}$ and CORRADO FICORELLA ${ }^{1,2}$ \\ ${ }^{1}$ Medical Oncology, St. Salvatore Hospital; ${ }^{2}$ Department of Biotechnological and Applied Clinical Sciences, \\ University of L'Aquila; ${ }^{3}$ Department of Radiation Oncology; ${ }^{4}$ Division of Emergency Radiology, St. Salvatore \\ Hospital, I-67100 L'Aquila; ${ }^{5}$ Medical Oncology, Campus Bio-Medico University, I-00128 Rome, Italy
}

Received June 6, 2018; Accepted September 18, 2018

DOI: $10.3892 / \mathrm{ol} .2018 .9561$

\begin{abstract}
The most frequent site of recurrence in breast cancer (BC) is the bone, particularly in patients with 'luminal-like' disease. Denosumab has been shown to prevent aromatase inhibitors (AIs) induced bone resorption in postmenopausal early BC patients and reduce skeletal-related events (SREs) in bone metastatic breast cancer (BMBC). A 'real life' analysis of $90 \mathrm{BMBC}$ patients treated with denosumab was performed. Eighty-six patients $(95.6 \%)$ had 'luminal-like' disease, 72 ( $80 \%$ ) had bone metastases at the time of first recurrence of disease. Among 50 patients with metachronous 'luminal-like' disease, $40(80 \%)$ had first recurrence to the bone. Among these patients median time to skeletal recurrence (TSkR) was shorter for patients who were previously exposed to AIs compared to those who were not (53.0 vs. 102.0 months, respectively; $\mathrm{P}=0.0300)$ and longer for patients previously treated with tamoxifen compared to those who were not (102.0 vs. 59.0 months, respectively; $\mathrm{P}=0.0466$ ). Both of them were not confirmed at multivariate analysis. In the overall population, 17 first SREs were observed (16 radiation therapy) and median time to first SRE was not reached. A statistically significant difference in the incidence of SREs was detected only between patients with exclusively osteolytic bone metastases vs. those
\end{abstract}

Correspondence to: Dr Alessio Cortellini, Medical Oncology, St. Salvatore Hospital, Via Vetoio, I-67100 L'Aquila, Italy

E-mail: alessiocortellini@gmail.com

Dr Katia Cannita, Department of Biotechnological and Applied Clinical Sciences, University of L'Aquila, Via Vetoio, I-67100 L'Aquila, Italy

E-mail:kcannita@gmail.com

${ }^{*}$ Contribuited equally

Key words: denosumab, bone, breast cancer, aromatase inhibitors, bone recurrence without $(\mathrm{P}=0.013)$. The presence of exclusively-osteolytic bone metastases was the only factor significantly associated with a shorter time to first SRE ( $\mathrm{P}=0.011)$. The only $\mathrm{G} 3$ toxicity reported was hypocalcemia in one patient. No osteonecrosis of the jaw events (ONJ) occurred. This study demonstrated that a pro-active attitude enables the treatment of the majority of patients with denosumab without significant class-related toxicities. The majority of SREs were from radiation therapy, so pain still remains the clinical hallmark of bone metastases, particularly for osteolytic ones. The suggestion that estrogen deprivation with AIs can favor a 'bone-related' risk conditions for developing bone metastases must be considered with caution and surely needs further validations.

\section{Introduction}

Breast cancer $(\mathrm{BC})$ is the most frequent tumor and the second leading cause of cancer death among women, with an estimate rate of about 250.000 new cases in 2016 (1). Despite the increase in chances of cure, approximately $20-45 \%$ of affected patients will develop metastases (2), particularly bone metastases in $60-80 \%$ of cases (3), bone-only metastases in $17-37 \%$ (4), and from 25 to $40 \%$ of patients have bone metastases at the diagnosis (3). Study data suggest that bone-only patients survive more than others (5). In a recent 'real-life' study of metastatic $\mathrm{BC}(\mathrm{MBC})$ patients, the median overall survival (OS) was 37.22 months (6), while some studies reported a median OS up to 72 months for bone-only patients (7).

Microarray analyses identified different gene expression profiles in $\mathrm{BC}$, thus differentiating molecular subgroups with different clinical course; several studies evaluated the association between subgroups and metastatic spread, showing that bone is the most common metastatic site in the luminal A $(66.6 \%)$, luminal B (71.4\%) and luminal/HER2+ tumors $(65 \%)$, while it is less frequently involved in basal-like tumors (39\%) (8). So, the expression of hormone receptors in BC is associated with a higher risk of developing bone metastases, but their presence does not necessarily imply that the metastatic 
involvement remains confined exclusively to the bone $(9,10)$. Indeed, experimental evidences prove that $\mathrm{BC}$ metastasis to the bone is mediated by a specific set of genes beyond those involved in the development of the primary tumor (11).

Osteoporosis, a process of bone mineral density (BMD) reduction, is accelerated by estrogen deficiency in postmenopausal women. Tamoxifen reduces BMD in premenopausal women, while promotes bone formation in postmenopausal patients. On the other hand, adjuvant aromatase inhibitors (AIs) therapy enhances the BMD decrease to about $2.5 \%$ per year, due to a long-lasting significant deprivation of circulatory and tissue estrogens (12). In the bone companion study of the MA.17 trial, patients treated with anastrozole reported a significant decreases in BMD ( 4\%), compared to those treated with tamoxifen (13). Due to osteoporosis, the bone microarchitecture is impaired and the microenvironment is modified. The 'seed and soil' hypothesis, proposed by Paget more than a hundred years ago (14), speculates that pro-metastatic tumor cells (the 'seed') take root in specific organ sites (the 'soil') where the microenvironment is favorable for metastasis. The primary tumor can promote metastasis by inducing the creation of a permissive microenvironment in a secondary organ site, termed the pre-metastatic niche $(15,16)$. The alteration of bone health associated with osteoporosis may provide fertile soil for the activation of the metastatic cascade, from the seeding of tumor cells to the activation of indolent micrometastases and finally to the expansion of bone lesions (17).

Several large randomized trials of adjuvant bisphosphonates vs. placebo showed an improvement, in both disease-free survival (DFS) and OS, in women with early BC treated with endocrine therapy (18-21). The role of denosumab in the prevention of AI-induced bone resorption was demonstrated in the ABCSG-18 phase III trial, which evaluated the effects of adjuvant denosumab in postmenopausal patients with early $\mathrm{BC}$ receiving AIs (22).

It is well known that bone metastases negatively affect patients' quality of life. Bisphosphonates showed to improve it, by reducing pain and the consequent consumption of analgesics, but they did not demonstrate to prolong survival (23).

Bisphosponates like zoledronic acid, limit the loss of bone density, by binding and blocking the enzyme farnesyl diphosphate synthase (FPPS) in the HMG-CoA reductase pathway, leading to inhibition of both osteoclastogenesis, cell survival, and cytoskeletal dynamics, which is vital for maintaining the 'ruffled border' that is required for contact between a resorbing osteoclast and a bone surface. Denosumab is a human monoclonal antibody which acts on 'pre-osteoclasts'. These precursors express on their cell surface receptors called RANK (receptor activator of nuclear factor-kappa B). RANK is activated by RANKL (the RANK-Ligand), which exists as cell surface molecules on osteoblasts and this binding promotes the maturation of pre-osteoclasts into osteoclasts. Denosumab proved to be more effective than zoledronic acid in terms of pain reduction, allowing a smaller percentage of patients makes use of strong opioids (24).

In the phase 3 study published by Stopeck et al (25), in 2010, 2049 patients with bone MBC (BMBC), were randomized to receive denosumab or zoledronic acid. The median time to first skeletal-related event (SRE) was 26.4 months in the group of patients treated with zoledronic acid, while it had not yet been reached in the group treated with denosumab, with a reduction in terms of time to first SRE by $18 \%$ over zoledronic acid (25). The subsequent uploaded data showed a median time to first SRE in the denosumab arm of 32.4 months (26). Moreover, denosumab demonstrated to decrease the risk of occurrence of multiple SREs by $23 \%$ and to reduce the skeletal morbidity rate (ratio between the number of SREs per patient divided by the patient of the time at risk) by $22 \%$ vs. zoledronic acid. Overall survival and disease progression were similar in the two groups. As to adverse events, pyrexia, bone pain, arthralgia, renal failure and hypercalcemia were more frequent during treatment with zoledronic acid, while hypocalcemia and toothache during treatment with denosumab. The risk of osteonecrosis of the jaw $(\mathrm{ONJ})$ was not higher with denosumab compared to zoledronic acid $(\mathrm{P}=0.39)(25)$.

Here we report a 'real life' multicenter retrospective analysis of BMBC patients treated with denosumab, focusing both to clinical outcomes commonly related to the treatment (safety and efficacy in reduce skeletal related events) and to the possible correlations between patients/diseases' features and clinical patterns of recurrence to the bone.

\section{Patients and methods}

Study design and statistical analysis. A retrospective analysis of BMBC patients treated with denosumab, at the medical oncology departments of St. Salvatore Hospital in L'Aquila and Campus Bio-medico University Hospital in Rome, was conducted. Data cut-off was August 2017. Comorbidities were classified according to the Cumulative Index Rating Scale (CIRS) (27). Estrogen and Progesterone Receptor expressions were evaluated by immunohistochemistry (IHC), using Dako monoclonal antibodies. HER 2 analysis was performed by IHC on paraffin embedded tissue from the primary tumor and/or metastatic site (Hercept-Test ${ }^{\circledR}$, Genentech Inc. subject to licenses held by Dako Denmark A/S, Glostrup, Denmark and F. Hoffmann-La Roche Ltd., Basel, Switzerland). Fluorescence in situ hybridization (FISH) and silver in situ hybridization (SISH) were used for cases of doubtful interpretation. 'Luminal-like' disease was defined in any case of Estrogen and/or Progesterone Receptor expression. Toxicity was registered according to the National Cancer Institute Common Toxicity Criteria (v4.0). Clinical evaluation of bone metastases was performed by radiographic imaging (X-ray, computed tomography scan or magnetic resonance) every three months or as clinically indicated up to death or last contact.

Definition of SRE included pathological fractures (not due to major trauma), radiation therapy on a bone segment, bone surgery or spinal cord compression (28). Hypercalcemia of malignancy was not considered among SREs. Subsequent events which occurred within 30 days of each other were not counted as separate events but rather unique (for example, a surgery to repair a fracture or multiple doses of radiation therapy during a treatment cycle). Only SREs occurred during treatment with denosumab were included in the analysis. Time to first SRE was defined as the interval from the start of denosumab to the onset of the first SRE (but not within the first month of treatment). Median time to skeletal recurrence (TSkR) was defined as the length of time from the surgical radicalization of the primary tumor to the diagnosis of first 
skeletal metastasis (it was calculated only for patients with metachronous recurrence to the bone). OS was defined as the interval from the start of denosumab to death or last contact.

Subgroup analyses were performed among patients according to the following variables: elderly status ( $<$ vs. $\geq$ of 70 years) (29), ECOG-PS (Eastern Cooperative Oncology Group Performance Status) (0/1 vs. 2), CIRS stage (primary/intermediate vs. secondary), 'luminal-like' disease (yes vs. no), HER2 status (positive vs. negative), menopausal status, extension of disease (bone only vs. non-bone only), visceral involvement (excluding lymph nodes) (yes vs. no), previous bisphosphonates (yes vs. no), number of bone metastases ( 1 vs. $\geq 1$ ), involvement of axial bones (yes vs. no), exclusively-osteolytic type of metastases (yes vs. no).

Patient eligibility. Patients were eligible if they had histologically confirmed diagnosis of $\mathrm{BC}$, radiological confirmation of at least one bone metastasis; age $\geq 18$ years; adequate haematological, renal and hepatic functions; albumin-adjusted serum calcium between 8.1 and $10.4 \mathrm{mg} / \mathrm{dl}$. Previous intravenous bisphosphonate therapy was allowed. Exclusion criteria were recent ( $<3$ months) surgery of the oral cavity or inflammatory untreated dental-periodontal or peri-implant disease. All patients performed an orthopantomography and a dental examination at baseline and twice a year thereafter. All patients provided written informed consent to the proposed treatment and to participate to this analysis. To guarantee the confidentiality of personal data for deceased patients, all the available procedures to ensure anonymity have been used. The procedures followed were in accordance with the precepts of Good Clinical Practice and the ethical standards of local responsible committee on human experimentation (Comitato Etico per le province di L'Aquila e Teramo).

Treatment. All patients received a subcutaneous injection of denosumab (XGEVA ${ }^{\circledR}$, Amgen Europe B.V. Breda, The Netherlands) $120 \mathrm{mg}$ every 4 weeks. A daily calcium ( $\geq 500 \mathrm{mg}$ ) and vitamin $\mathrm{D}(\geq 1,000 \mathrm{U})$ oral supplement was recommended. All patients received concomitant specific antineoplastic treatment, chemotherapy or endocrine therapy (Table I).

Statistical analysis. Median TSkR, median time to first SRE and median OS were evaluated using the Kaplan-Meier method (30). Median period of follow-up was calculated according to the reverse Kaplan-Meier method (31). $\chi^{2}$ and Fisher's exact test were used to compare the incidence of SREs among subgroups, using the appropriate test according to the sample size in contingency tables for each comparison $(32,33)$. Log-rank (34) was used to compare TSkR among subgroups. Cox proportional hazards regression (35) was used for univariate and multivariate analyses of clinical outcomes among subgroups (time to first SRE and OS). For statistical analysis MedCalc Statistical Software, v18.6 (MedCalc Software bvba, Ostend, Belgium; http://www.medcalc.org; 2018) was used.

\section{Results}

Patients'features. From July 2012 to August 201790 consecutive BMBC patients were treated with denosumab. Clinical features of patients are summarized in Table I. One out of
Table I. Patients' features.

Clinical feature

No. of patients $(\%)$

Total no. of patients

$90(100.0)$

Sex

Male

1 (1.1)

Female

89 (98.9)

Age

Non elderly 69 (76.7)

Elderly

$21(23.3)$

ECOG PS

$0-1$

$84(93.3)$

$\geq 2$

$6(6.7)$

CIRS (Comorbidity)

Primary/intermedieate $\quad 73(81.1)$

Secondary

$17(18.9)$

Luminal-like

$86(95.6)$

HER2 positive

$13(14.4)$

$4(4.4)$

Triple negative

Type of disease

Synchronous $36(40.0)$

Metachronous

$54(60.0)$

Menopausal status

Yes

$74(82.2)$

No

$16(17.8)$

Onset localization of metastases

Bone

$72(80.0)$

Visceral

$18(20.0)$

80 (88.9)

35 (38.9)

38 (42.2)

$81(90.0)$

Axial bone metastases

$48(53.3)$

$42(46.7)$

Others

$43(47.8)$

$70(77.8)$

$52(57.8)$

13 (14.4)

$29(32.2)$

14 (15.6)

5 (5.6)

$27(30.0)$

Previous bisphosphonates

The median age of pateints was 58 years (age range, 26-91). ECOG-PS, eastern cooperative oncology group-performance status; CIRS, cumulative illness rating scale; CDK, cyclin-dependent kinase; HER2, human epidermal growth factor 2.

90 patients was male, median age was 61 years (range 26-91). Twenty-one patients (23.3\%) were elderly, $6(6.7 \%)$ had ECOG-PS $\geq 2,17$ (18.9\%) had a secondary CIRS stage and 
$74(82.2 \%)$ were in menopausal status. Eighty-six patients (95.6\%) had 'luminal-like' disease, 72 (80\%) had bone metastases at the time of diagnosis of metastatic disease, 18 (20\%) had the firs recurrence of disease to visceral organs. Disease-oriented systemic treatments were concomitantly administered to all patients; 27 (30\%) patients received previous bisphosphonate therapy. Fifty-four patients $(60 \%)$ had a metachronous disease; clinical features of these patients are listed in Table II. Among 50 patients with metachronous 'luminal-like' disease, $40(80 \%)$ had first recurrence to the bone, $10(20 \%)$ to the visceral organs. Nineteen $(38 \%)$ were previously treated with tamoxifen, 26 patients (52\%) with AIs adjuvant therapy (including 10 to both tamoxifen and AIs).

Clinical patterns of disease recurrence to the bone. Among 40 patients with metachronous 'luminal-like' disease and first recurrence to the bone, fisher exact test did not show any statistically significant difference between previously exposed to AIs vs. not $(\mathrm{P}=0.4896)$ and to tamoxifen vs. not $(\mathrm{P}=1.0000)$. Among these patients median TSkR was 70.0 months (95\% CI: 50.0-95.0). At univariate analysis with log-rank test, median TSkR was significantly shorter for patients who were previously exposed to AIs compared to those who were not (53.0 vs 102.0 months, respectively; $\mathrm{P}=0.0300$ ). Median TSkR was also significantly longer for patients previously treated with tamoxifen compared to those who were not (102.0 vs. 59.0 months, respectively; $\mathrm{P}=0.0466$; Fig. 1). At multivariate analysis, neither previous exposure to AIs ( $\mathrm{HR}=1.66,95 \%$ CI: $0.48-5.72)$ nor treatment with tamoxifen ( $\mathrm{HR}=0.78,95 \%$ CI: 0.22-2.75) were confirmed as independent predictors for TSkR.

Clinical outcomes. All 90 patients were evaluable for clinical outcomes, as summarized in Table III. A median number of 18.5 cycles of denosumab was administered. In the overall population, 17 first SREs were observed, represented by 16 radiation therapy on a bone segment and 1 pathological fracture, with an incidence of $18.8 \%$ (95\% CI: 11.4-28.5). Among patients who developed a SRE, 5 (29.4\%) developed a subsequent SRE (5 radiation therapy on a bone segment). As shown in Fig. 2, a statistically significant difference in the incidence of SREs was detected only between patients with exclusively-osteolytic bone metastases vs. not $(\mathrm{P}=0.013)$. Specifically, among the first group (48 patients with exclusively-osteolytic metastases) $14(29.2 \%)$ SREs were observed (95\% CI: 15.9-48.9) compared to 3 SREs (7.1\%) among the second group (95\% CI: 1,4-20.8) (42 patients with other types of bone metastases). After a median follow up of 33 months, median time to first SRE was not reached (Fig. 3) and median OS was 40.0 months (95\% CI: 34.0-48.0). At univariate analysis, only type of bone metastases was significantly correlated to time to first SRE in favor of other than exclusively-osteolytic ones $(\mathrm{P}=0.011)$ (Table IV). As to OS, at univariate analysis ECOG-PS 0/1 $(\mathrm{P}=0.027)$, bone-only disease $(\mathrm{P}=0.004)$ and non-visceral disease $(\mathrm{P}=0.023)$ were significantly correlated to a better $\mathrm{OS}$, while multivariate analysis confirmed just ECOG-PS $(\mathrm{P}=0.006)$ and bone-only disease $(\mathrm{P}=0.035)$ as independent predictors for OS (Table V).

Safety. In the present analysis, we reported only class-specific adverse events which could be related to denosumab and
Table II. Clinical features of patients with metachronous disease.

\begin{tabular}{lc}
\hline Clinical feature & No. of patients $(\%)(\mathrm{n}=54)$ \\
\hline Triple negative & $4(7.4)$ \\
Luminal-like & $50(92.6)$ \\
Adjuvant hormonal therapy & \\
Aromatase inhibitors & $26(52)$ \\
Tamoxifen & $19(38)$ \\
Onset localization of metastases & \\
Bone & $40(80)$ \\
Visceral & $10(20)$ \\
\hline
\end{tabular}

Table III. Efficacy data.

\begin{tabular}{lc}
\hline Variables & Value \\
\hline Evaluable patients, no. of patients (\%) & $90(100)$ \\
Incidence of SRE, (\%) & $18.8^{\mathrm{a}}$ \\
Radiation therapy, no. of patients (\%) & $16(17.8)$ \\
Pathological fracture, no. of patients (\%) & $1(1.1)$ \\
Median time to first SRE, months (range) & Not reached (1-61) \\
Median OS time, months & $40.0(1-61)^{\mathrm{b}}$ \\
No. of mortalities & 38 \\
\hline
\end{tabular}

a95\%CI, 11.4-28.5; b95\%CI, 35.0-48.0. SRE, skeletal-related events; OS, overall survival; CI, confidence interval.

not to disease-oriented treatments concomitantly administered (Table VI). All patients were evaluable for toxicity. Four patients $(4.4 \%)$ discontinued denosumab due to adverse events. The only G3 toxicity reported was hypocalcemia in a patient, with a history of total thyroidectomy, completely recovered by strengthening of calcium and vitamin D support. Decrease in serum calcium levels was in most cases mild, recovered in a short time (within 2 weeks) with an increased in oral calcium and vitamin D support and was not accompanied by clinical complications. No ONJ events occurred. Patients experiencing toothache $(10.0 \%)$ did not develop ONJ, while two patients (3.1\%) reported dental infections in absence of radiographic signs of bone remodeling.

\section{Discussion}

Our 'real life' safety data confirmed the good tolerability of denosumab. We reported $7.8 \%$ of flu-like symptoms and no case of renal injury. We did not report cases of ONJ, even in patients who experiencing toothache (12.5\%). As previously mentioned, all patients underwent orthopantomography and subsequent maxillofacial visit before starting denosumab, to identify possible risk factors such as recent dental alveolar surgery ( $<3$ months), dental-periodontal or peri-implant inflammatory disease, incongruous removable dentures or poor oral hygiene, which could be responsible for an increased risk of 

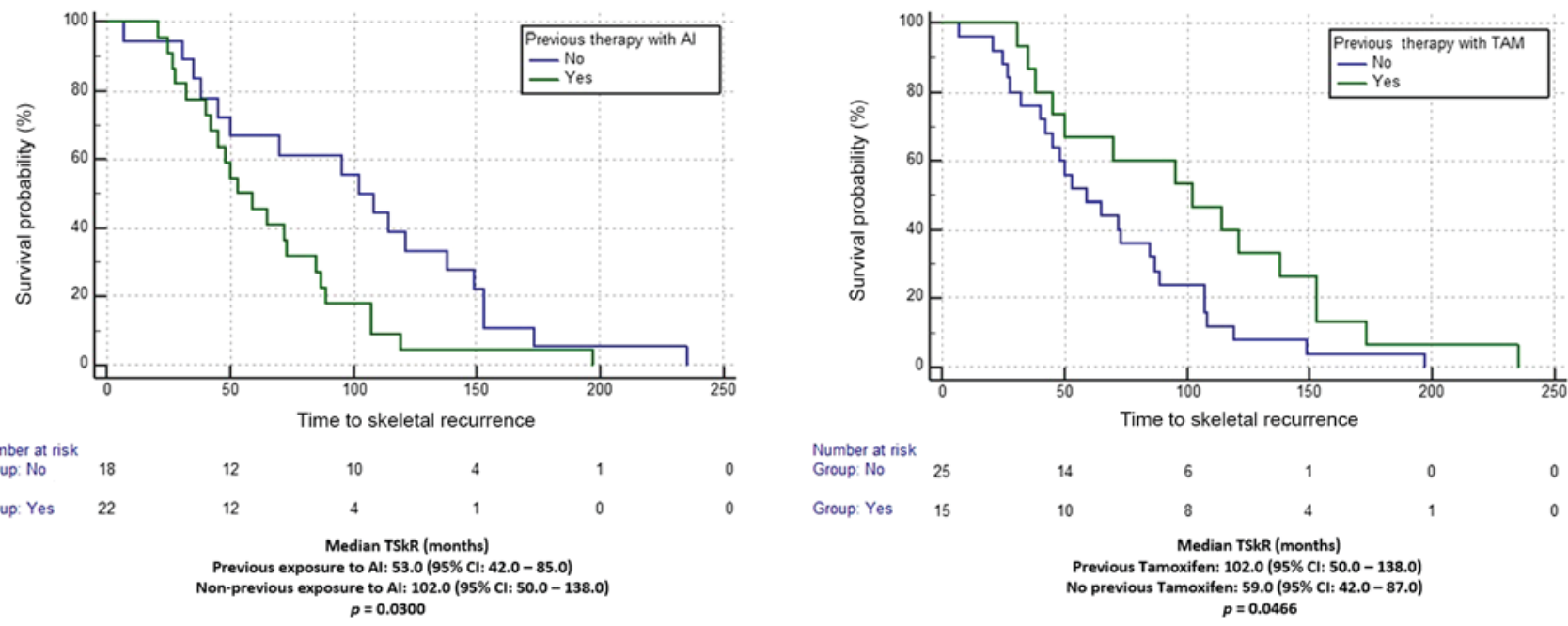

Figure 1. Log-rank test for median TSkR, measured in months, for previous exposure to AI during adjuvant therapy vs. not, and previous tamoxifen adjuvant therapy vs. not. TSkR, time to skeletal recurrence; AI, aromatase inhibitors.

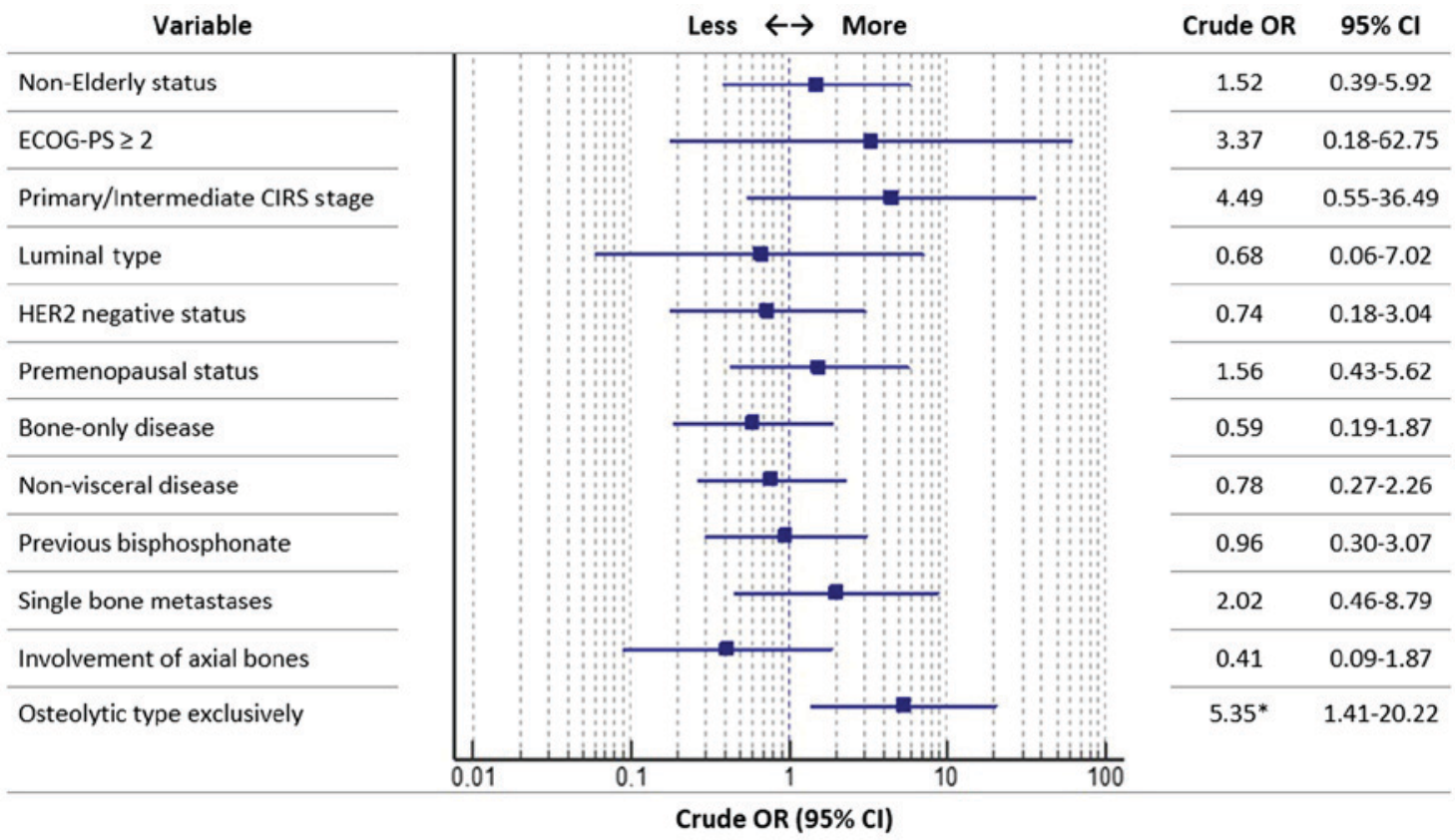

Figure 2. Forest plot graph for incidence of SRE. SRE, skeletal related events; OR, Odds Ratio; "statistically significant.
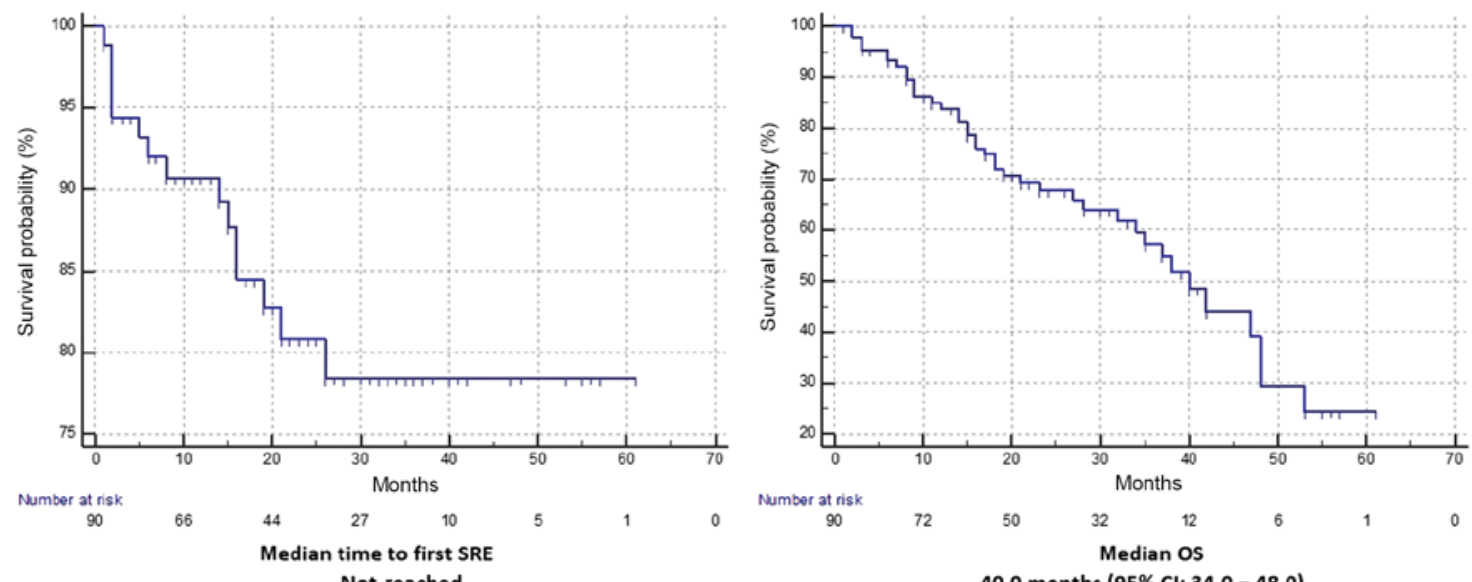

Not reached

40.0 months $(95 \% \mathrm{Cl}: 34.0-48.0)$

Figure 3. Kaplan-Meier survival estimate for time to first SRE and OS in the overall population. SRE, skeletal related event; OS, overall survival. 
Table IV. Univariate analysis for time to first SRE.

Univariate analysis for time to first SRE

\begin{tabular}{|c|c|c|c|}
\hline \multirow{2}{*}{ Clinical features } & \multirow[b]{2}{*}{ No. of patients } & \\
\hline & & HR $(95 \%$ CI $)$ & P-value \\
\hline \multicolumn{4}{|l|}{ Age } \\
\hline Non elderly vs. elderly & 69 vs. 21 & $0.87(0.25-3.06)$ & 0.836 \\
\hline \multicolumn{4}{|l|}{ ECOG-PS } \\
\hline $0-1$ vs. $\geq 2$ & 84 vs. 6 & Not computable & 0.953 \\
\hline \multicolumn{4}{|l|}{ CIRS stage } \\
\hline Primary/intermediate vs. secondary & 73 vs. 17 & $0.29(0.03-2.23)$ & 0.237 \\
\hline \multicolumn{4}{|l|}{ Luminal-like disease } \\
\hline Yes vs. no & 86 vs. 4 & $1.34(0.17-10.23)$ & 0.777 \\
\hline \multicolumn{4}{|l|}{ HER2 status } \\
\hline Positive vs. negative & 13 vs. 77 & $1.13(0.32-3.96)$ & 0.839 \\
\hline \multicolumn{4}{|l|}{ Menopausal status } \\
\hline Yes vs. no & 74 vs. 16 & $0.76(0.28-2.08)$ & 0.605 \\
\hline \multicolumn{4}{|l|}{ Bone-only disease } \\
\hline Yes vs. no & 35 vs. 55 & $1.76(0.62-5.03)$ & 0.284 \\
\hline \multicolumn{4}{|l|}{ Visceral disease } \\
\hline Yes vs. no & 38 vs. 52 & $1.26(0.48-3.27)$ & 0.632 \\
\hline \multicolumn{4}{|l|}{$>1$ bone metastases } \\
\hline Yes vs. no & 10 vs. 80 & $0.52(0.14-1.83)$ & 0.311 \\
\hline \multicolumn{4}{|l|}{ Axial bone metastases } \\
\hline Yes vs. no & 81 vs. 9 & $0.40(0.11-1.43)$ & 0.161 \\
\hline \multicolumn{4}{|l|}{ Previous bisphosphonates } \\
\hline Yes vs. no & 27 vs. 63 & $1.27(0.44-3.62)$ & 0.655 \\
\hline \multicolumn{4}{|l|}{ Type of bone metastases } \\
\hline Osteolytic exclusively vs. others & 48 vs. 42 & $0.19(0.05-0.69)$ & $0.011^{\mathrm{a}}$ \\
\hline
\end{tabular}

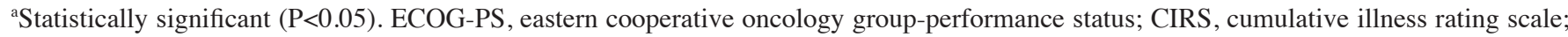
$\mathrm{SRE}$, skeletal-related events; HR, hazard ratio; CI, confidence interval.

develop ONJ. In our study, G2 hypocalcemia occurred in $3.1 \%$ and G3 hypocalcemia in $1.6 \%$ of patients. Almost all events of hypocalcemia occurred in the first 6 months of treatment, not related to clinical complications and a more adequate support of calcium and vitamin D solved them within a week.

We observed 17 first SREs; exclusively-osteolytic type of metastases is the only factor significantly related to the incidence of SREs and to median time to first SRE. As in most cases (16 out of 17) the SRE was represented by radiotherapy, performed with a palliative aim for bone pain, thus we could hypothesize that exclusively-osteolytic bone metastases are associated with a greater incidence of pain. Cancer-induced bone pain is a complex syndrome, which involve inflammatory, neuropathic, ischemic and cancer-specific mechanisms, and it is related to tumor growth, release of pain mediators by the cancer cells and damage to the sensory nerves caused by infiltration and/or compression by the tumor cells (36). A different impact on bone pain between osteolytic and osteoblastic lesions has never been clearly demonstrated. Osteolytic metastases are caused by proliferation and hypertrophy of osteoclasts. While inducing bone remodeling, osteoclasts release various acidic and lytic enzymes, causing bone degradation and a decrease in the $\mathrm{pH}$ of the tumor microenvironment; also local acidosis could probably be involved in the nociceptive stimulation of the primary afferents in the bone (37).

The $95.6 \%$ of our patients had 'luminal-like' disease. In line with that, a recent prospective study, aimed at identifying patterns of $\mathrm{BC}$ relapse according to the biological subtype, Luminal A and Luminal B tumors demonstrated a predominant rate of distant metastases to the bone, compared to HER2-enriched and triple-negative tumors (38).

Multivariate survival analysis showed that just ECOG-PS and bone-only disease result independent predictors for a longer OS. Several other studies reported an improved prognosis for bone-only MBC patients compared to patients with visceral or central nervous system metastases (39-41). In a recent retrospective analyses from the MD Anderson Cancer Center, median OS of bone-only MBC patients was 4.9 years (42). However bone-only disease and ECOG-PS were already been widely related with a longer OS $(4,43)$.

Interestingly, regarding patients with metachronous 'luminal-like' disease, at univariate analysis we found that 
Table V. Univariate and multivatiate analyses for OS.

\begin{tabular}{|c|c|c|c|c|c|}
\hline \multirow[b]{2}{*}{ Clinical features } & \multirow[b]{2}{*}{ No. of patients } & \multicolumn{2}{|c|}{ Univariate analysis for OS } & \multicolumn{2}{|c|}{ Multivariate analysis for OS } \\
\hline & & HR $(95 \% \mathrm{CI})$ & P-value & HR $(95 \% \mathrm{CI})$ & P-value \\
\hline \multicolumn{6}{|l|}{ Age } \\
\hline Non elderly vs. elderly & 69 vs. 21 & $1.45(0.70-2.99)$ & 0.313 & - & - \\
\hline \multicolumn{6}{|l|}{ ECOG-PS } \\
\hline $0-1$ vs. $\geq 2$ & 84 vs. 6 & $3.30(1.14-9.55)$ & $0.027^{\mathrm{a}}$ & $4.90(1.57-15.30)$ & $0.006^{\mathrm{a}}$ \\
\hline \multicolumn{6}{|l|}{ CIRS stage } \\
\hline Primary/intermediate vs. secondary & 73 vs. 17 & $1.75(0.82-3.72)$ & 0.144 & - & - \\
\hline \multicolumn{6}{|l|}{ Luminal-like disease } \\
\hline Yes vs. no & 86 vs. 4 & $1.54(0.46-5.08)$ & 0.476 & - & - \\
\hline \multicolumn{6}{|l|}{ HER2 status } \\
\hline Positive vs. negative & 13 vs. 77 & $1.02(0.44-2.34)$ & 0.952 & - & - \\
\hline \multicolumn{6}{|l|}{ Menopausal status } \\
\hline Yes vs. no & 74 vs. 16 & $0.93(0.55-1.55)$ & 0.792 & - & - \\
\hline \multicolumn{6}{|l|}{ Bone-only disease } \\
\hline Yes vs. no & 35 vs. 55 & $3.09(1.41-6.76)$ & $0.004^{\mathrm{a}}$ & $2.86(1.06-7.69)$ & $0.035^{\mathrm{a}}$ \\
\hline \multicolumn{6}{|l|}{ Visceral disease } \\
\hline Yes vs. no & 38 vs. 52 & $2.11(1.10-4.02)$ & $0.023^{\mathrm{a}}$ & $1.29(0.55-3.02)$ & 0.543 \\
\hline \multicolumn{6}{|l|}{$>1$ bone metastases } \\
\hline Yes vs. no & 10 vs. 80 & $0.64(0.22-1.86)$ & 0.420 & - & - \\
\hline \multicolumn{6}{|l|}{ Axial bone metastases } \\
\hline Yes vs. no & 81 vs. 9 & $1.06(0.32-3.47)$ & 0.916 & - & - \\
\hline \multicolumn{6}{|l|}{ Previous bisphosphonates } \\
\hline Yes vs. no & 27 vs. 63 & $0.81(0.42-1.55)$ & 0.525 & - & - \\
\hline \multicolumn{6}{|l|}{ Type of bone metastases } \\
\hline Osteolytic exclusively vs. others & 48 vs. 42 & $1.22(0.64-2.33)$ & 0.527 & - & - \\
\hline
\end{tabular}

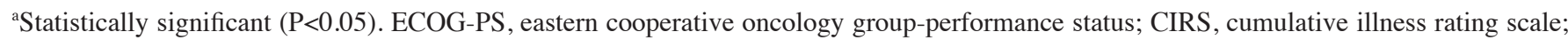
HR, hazard ratio; CI, confidence interval; OS, overall survival.

median TSkR was significantly shorter for patients who were previously exposed to AIs compared to those who were not (53.0 vs 102.0 months, respectively; $\mathrm{P}=0.0300$ ), even if the significance was not confirmed at multivariate analysis, where only a trend was maintained. These findings are aligned with the abovementioned 'seed and soil' hypothesis (36), suggesting that AI-induced osteoporosis could increase the risk of developing bone metastases. Surely these data are not conclusive; we must take into account the strong limitations of our analysis: the small sample size (40 patients), the retrospective nature and the selection biases. A certain fact is that tumor cells interfere with the bone homeostasis by secreting growth factors, which stimulate bone resorption; bone resorption, in turn, leads to release of factors promoting tumor growth in a 'vicious cycle' of tumor expansion and bone destruction (44). Bisphosphonates and denosumab can block this cycle and prevent bone loss. In order to clarify if AIs could have a certain role in developing bone metastases, we have already planned a multicenter retrospective confirmatory study, which will evaluate clinical pattern of disease progression in early 'luminal-like' BC patients who underwent adjuvant hormonal treatments.
Table VI. Class-related toxicy data.

\begin{tabular}{lccc}
\hline & \multicolumn{2}{c}{ No. of patients (n=90) (\%) } \\
\cline { 2 - 4 } Grade & Any grade & G3 & G4 \\
\hline Acute phase reactions & $2(2.2)$ & - & - \\
Hypocalcemia & $17(18.9)$ & $1(1.1)$ & - \\
Hypercalcemia & $1(1.1)$ & - & - \\
Fever & $12(13.3)$ & - & - \\
Bone pain/arthralgia & $24(26.7)$ & - & - \\
Toothache & $9(10.0)$ & - & - \\
Dental infections & $2(2.2)$ & - & - \\
\hline
\end{tabular}

Denosumab have demonstrated to improve osteoporosis progression in early $\mathrm{BC}$ postmenopausal patients receiving AIs. Assuming that AIs adjuvant treatments could create a 'bone-related' risk conditions for developing bone metastases, could denosumab have a role in prevention of this risk conditions? 
The present study showed that denosumab in our hands have a good safety profile, and a pro-active attitude let us to treat in a 'real life' setting the majority of patients without significant class-related toxicities and no ONJ events. The majority of SRE were radiation therapy, so pain still remain the clinical hallmark of bone metastases, particularly of osteolytic ones. The suggestion that estrogen deprivation with AIs can favour a 'bone-related' risk conditions for developing bone metastases must be considered with caution and surely needs further validations; our next multicenter confirmatory study will try to shed light on this topic.

\section{Acknowledgements}

Not applicable.

\section{Funding}

No funding was received.

\section{Availability of data and materials}

The datasets used during the present study are available from the corresponding author upon reasonable request.

\section{Authors' contributions}

$\mathrm{AC}, \mathrm{KC}, \mathrm{VC}, \mathrm{DS}, \mathrm{AI}, \mathrm{GP}, \mathrm{PB}$ and $\mathrm{PF}$ and $\mathrm{CF}$ conceived and designed the study. AP, FP, CDO, LV, OV, LZ, TS, and PLB collected the data. AC, PB, PF and VC wrote the paper. KC, DS, $\mathrm{CF}$ and GP reviewed and edited the manuscript. All authors read and approved the manuscript and agree to be accountable for all aspects of the research in ensuring that the accuracy or integrity of any part of the work are appropriately investigated and resolved.

\section{Ethics approval and consent to participate}

All patients provided written informed consent to treatment. The procedures followed were in accordance with the ethical standards of the Local Responsible Committees on Human Experimentation (Comitato etico per le province di L'Aquila e Teramo).

\section{Patient consent for publication}

Not applicable.

\section{Competing interests}

The authors declare that they have no competing interests.

\section{References}

1. Siegel RL, Miller KD and Jemal A: Cancer statistics, 2016. CA Cancer J Clin 66: 7-30, 2016.

2. Karrison TG, Ferguson DJ and Meier P: Dormancy of mammary carcinoma after mastectomy. J Natl Cancer Inst 91: 80-85, 1999.

3. Coleman RE: Skeletal complications of malignancy. Cancer 80 (8 Suppl): S1588-S1594, 1997.

4. Ahn SG, Lee HM, Cho SH, Lee SA, Hwang SH, Jeong J and Lee HD: Prognostic factors for patients with bone-only metastasis in breast cancer. Yonsei Med J 54: 1168-1177, 2013.
5. Jacobson AF, Shapiro CL, Van den Abbeele AD and Kaplan WD: Prognostic significance of the number of bone scan abnormalities at the time of initial bone metastatic recurrence in breast carcinoma. Cancer 91: 17-24, 2001.

6. Gobbini E, Ezzalfani M, Dieras V, Bachelot T, Brain E, Debled M, Jacot W, Mouret-Reynier MA, Goncalves A, Dalenc F, et al: Time trends of overall survival among metastatic breast cancer patients in the real-life ESME cohort. Eur J Cancer 96: 17-24, 2018.

7. Briasoulis E, Karavasilis V, Kostadima L, Ignatiadis M, Fountzilas G and Pavlidis N: Metastatic breast carcinoma confined to bone: Portrait of a clinical entity. Cancer 101: 1524-1528, 2014.

8. Kennecke H, Yerushalmi R, Woods R, Cheang MC, Voduc D, Speers CH, Nielsen TO and Gelmon K: Metastatic behavior of breast cancer subtypes. J Clin Oncol 28: 3271-3277, 2010.

9. Bundred NJ, Walker RA, Ratcliffe WA, Warwick J, Morrison JM and Ratcliffe JG: Parathyroid hormone related protein and skeletal morbidity in breast cancer. Eur J Cancer 28: 690-692, 1992.

10. Vargas SJ, Gillespie MT, Powell GJ, Southby J, Danks JA, Moseley JM and Martin TJ: Localisation of parathyroid hormone-related protein mRNA expression in breast cancer and metastatic lesions by in situ hybridisation. J Bone Miner Res 7: 971-979, 1992.

11. Kang Y, Siegel PM, Shu W, Drobnjak M, Kakonen SM, Cordón-Cardo C, Guise TA and Massagué J: A multigenic program mediating breast cancer metastasis to bone. Cancer Cell 3: 537-549, 2003 .

12. Geisler J, Lønning PE, Krag LE, Løkkevik E, Risberg T, Hagen AI, Schlichting E, Lien EA, Ofjord ES, Eide GE, et al: Changes in bone and lipid metabolism in postmenopausal women with early breast cancer after terminating 2 -year treatment with exemestane: A randomised, placebo-controlled study. Eur J Cancer 42: 2968-2975, 2006.

13. Perez EA, Josse RG, Pritchard KI, Ingle JN, Martino S, Findlay BP, Shenkier TN, Tozer RG, Palmer MJ, Shepherd LE, et al: Effect of letrozole versus placebo on bone mineral density in women with primary breast cancer completing 5 or more years of adjuvant tamoxifen: A companion study to NCIC CTGMA. 17. J Clin Oncol 24: 3629-3635, 2006.

14. Paget S: The distribution of secondary growths in cancer of the breast. Cancer Metastasis Rev 8: 98-101, 1889.

15. Chin AR and Wang SE: Cancer tills the premetastatic field: Mechanistic basis and clinical implications. Clin Cancer Res 22: 3725-3733, 2016.

16. Liu Y and Cao X: Characteristics and significance of the pre-metastatic niche. Cancer Cell 30: 668-681, 2016.

17. Lipton A, Chapman JW, Leitzel K, Garg A, Pritchard KI, Ingle JN, Budd GT, Ellis MJ, Sledge GW, Rabaglio M, et al: Osteoporosis therapy and outcomes for postmenopausal patients with hormone receptor-positive breast cancer: NCIC CTG MA.27. Cancer 123: 2444-2451, 2017.

18. Gnant M, Mlineritsch B, Stoeger H, Luschin-Ebengreuth G, Heck D, Menzel C, Jakesz R, Seifert M, Hubalek M, Pristauz G, et al: Adjuvant endocrine therapy plus zoledronic acid in premenopausal women with early-stage breast cancer: 62-month follow-up from the ABCSG-12 randomised trial. Lancet Oncol 12: 631-641, 2011.

19. Gnant M, Mlineritsch B, Luschin-Ebengreuth G, Stoeger H, Dubsky P, Jakesz R, Singer C, Eidtmann H, Fesl C, Eiermann W, et al: Long-term follow-up in ABCSG-12: Significantly improved overall survival with adjuvant zoledronic acid in premenopausal patients with endocrine-receptor-positive early breast cancer. Cancer Res 71 (3 Suppl): S1-S2, 2011.

20. Coleman RE, Marshall H, Cameron D, Stoeger H, Dubsky P, Jakesz R, Singer C, Fest C, Eiermann W, Marth C, et al: Breast cancer adjuvant therapy with zoledronic acid. N Engl J Med 365: 1396-1405, 2011.

21. Yan T, Yin W, Zhou Q, Zhou L, Jiang Y, Du Y, Shao Z and $\mathrm{Lu} \mathrm{J}$ : The efficacy of zoledronic acid in breast cancer adjuvant therapy: A meta-analysis of randomised controlled trials. Eur J Cancer 48: 187-195, 2012.

22. Gnant M, Pfeile Gr, Dubsky PC, Hubalek M, Greil R, Jakesz R, Wette V, Balic M, Haslbauer F, Melbinger E, et al: Adjuvant denosumab in breast cancer (ABCSG-18): A multicentre, randomised, double-blind, placebo-controlled trial. Lancet 386: 433-443, 2015.

23. Coleman RE, Smith P and Rubens RD: Clinical course and prognostic factors following bone recurrence from breast cancer. $\mathrm{Br} \mathrm{J}$ Cancer 77: 336-340, 1998. 
24. Cleeland CS, Body JJ, Stopeck A, von Moos R, Fallowfield L, Mathias SD, Patrick DL, Clemons M, Tonkin K, Masuda N, et al: Pain outcomes in patients with advanced breast cancer and bone metastases: Results from a randomized, double-blind study of denosumab and zoledronic acid. Cancer 119: 832-838, 2013.

25. Stopeck AT, Lipton A, Body JJ, Steger GG, Tonkin K, de Boer RH, Lichinitser M, Fujiwara Y, Yardley DA, Viniegra M, et al: Denosumab compared with zoledronic acid for the treatment of bone metastases in patients with advanced breast cancer: A randomized, double-blind study. J ClinOncol 28: 5132-5139, 2010

26. Steger GG and Bartsch R: Denosumab for the treatment of bone metastases in breast cancer: Evidence and opinion. Ther Adv Med Oncol 3: 233-243, 2011.

27. Parmelee PA, Thuras PD, Katz IR and Lawton MP: Validation of the cumulative illness rating scale in a geriatric residential population. J Am Geriatr Soc 43: 130-137, 1995.

28. Van Poznak CH, Temin S, Yee GC, Janjan NA, Barlow WE, Biermann JS, Bosserman LD, Geoghegan C, Hillner BE, Theriault RL, et al: American Society of Clinical Oncology executive summary of the clinical practice guideline update on the role of bone-modifying agents in metastatic breast cancer. J ClinOncol 29: 1221-1227, 2011.

29. Tesarova P: Breast cancer in the elderly-Should it be treated differently? Rep Pract Oncol Radiother 18: 26-33, 2013.

30. Kaplan EL and Meier P: Nonparametric estimation of incomplete observations. J Am Stat Assoc 53: 457-481, 1958.

31. Schemper M and Smith TL: A note on quantifying follow-up in studies of failure time. Control Clin Trials 17: 343-346, 1997.

32. Fisher RA: On the interpretation of $\chi^{2}$ from contingency tables and the calculation of P. J Royal Stat Soc 85: 87-94, 1922.

33. Mantel N: Chi-square tests with one degree of freedom: Extensions of the Mendel-Haenszel procedure. J Am Stat Assoc 58: 690-700, 1963

34. Peto R and Peto J: Asymptomatically efficient rank invariant test procedures. J R Stat Soc A 135: 185-206, 1972.

35. Cox DR: Regression models and life tables (with discussion). J Royal Stat Soc (Series B) 74: 187-200, 1972.

36. Falk S and Dickenson AH: Pain and nociception: Mechanisms of cancer-induced bone pain. J Clin Oncol 32: 1647-1654, 2014.
37. Julius D and Basbaum AI: Molecular mechanisms of nociception. Nature 413: 203-210, 2001.

38. Ignatov A, Eggemann H, Burger E and Ignatov T: Patterns of breast cancer relapse in accordance to biological subtype. J Cancer Res Clin Oncol 144: 1347-1355, 2018.

39. Sherry MM, Greco FA, Johnson DH and Hainsworth JD: Metastatic breast cancer confined to the skeletal system. An indolent disease. Am J Med 81: 381-386, 1986.

40. Leone BA, Romero A, Rabinovich MG, Vallejo CT, Bianco A, Perez JE, Machiavelli M, Rodriguez R and Alvarez LA: Stage IV breast cancer: Clinical course and survival of patients with osseous versus extraosseous metastases at initial diagnosis. The GOCS (Grupo Oncologico Cooperativo del Sur) experience. Am J Clin Oncol 11: 618-622, 1988.

41. Perez JE, Machiavelli M, Leone BA, Romero A, Rabinovich MG, Vallejo CT, Bianco A, Rodriguez R, Cuevas MA and Alvarez LA: Bone-only versus visceral-only metastatic pattern in breast cancer: Analysis of 150 patients. A GOCS study. Grupo Oncológico Cooperativo del Sur. Am J Clin Oncol 13: 294-298, 1990.

42. Parkes A, Clifton K, Al-Awadhi A, Oke O, Warneke CL, Litton JK and Hortobagyi GN: Characterization of bone only metastasis patients with respect to tumor subtypes. NPJ Breast Cancer 4: 2, 2018.

43. Niikura N, Liu J, Hayashi N, Palla SL, Tokuda Y, Hortobagyi GN, Ueno NT and Theriault RL: Treatment outcome and prognostic factors for patients with bone-only metastases of breast cancer: A single-institution retrospective analysis. Oncologist 16: 155-164, 2011.

44. Roodman GD: Mechanisms of bone metastasis. N Engl J Med 350: $1655-1664,2004$

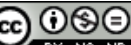

This work is licensed under a Creative Commons Attribution-NonCommercial-NoDerivatives 4.0 International (CC BY-NC-ND 4.0) License. 